\title{
The influence of language-specific and universal factors on acquisition of notion verbs
}

\author{
Rebecca Smyder \& Kaitlyn Harrigan*
}

\begin{abstract}
This study explores children's encoding of novel verbs referring to motion events, and finds influence of both language-specific and universal constraints on meaning. Motion verbs fall into two categories - manner verbs encode how a movement happens (run, swim), and path verbs encode the starting and ending point of a motion (enter, fall). Some languages express path more frequently in the verb (Spanish, Hebrew), and others manner more frequently (English, German). Our study builds on previous work demonstrating sensitivity to these language-specific distributions; expanding to test environmental factors representing a predictable universal distribution. We find that children are sensitive to both the languagespecific factors as well as the universal factors in motion verb acquisition.
\end{abstract}

Keywords. language acquisition; word learning; verb learning; motion verbs

1. Introduction. Learning verb meanings poses massive challenges to the learner-after all, any given scene displays almost infinite ambiguity, and even the event to which a verb refers contains many potential meaning referents. If a child sees their sibling jump from one room to the next and hears "hopping!" does the child automatically encode "hopping" as a jumping motion? Could "hopping" also mean entering the room or exiting the adjacent room? What about an action performed by the specific individual executing the hopping? Or the location in which this hopping is occurring? How does the learner isolate and encode the slice of meaning referred to by any verb? Ideally, we might imagine that in order to overcome such ambiguity children narrow down meanings by receiving exposures over a variety of contexts. However, we know this kind of robust evidence is not always available to the child, indicating that she must have some additional constraints guiding this mapping. Language acquisitionists have long investigated these constraints - what are they? Which are universal? Which are language-specific? And how does the learner come to acquire the language-specific biases? The current study explores children's encoding of novel verbs referring to motion events, manipulating both a language-specific cue, as well as what we hypothesize is a more universal constraint on verb meanings. We find that children show evidence of being influenced by both constraints in their mapping of novel motion verbs.

1.1. MOTION VERB TYPOLOGY. Verbs of motion fall into two basic categories: manner verbs (skip, roll), which describe how a movement happens; and path verbs, which describe the trajectory of the motion (enter, exit). Native English speakers might find the "what is hopping?" question rather intuitive - the default in English is to map a motion verb to a manner. However, this intuition is not universal — not all languages default to encoding manner. Talmy (2003) describes two types of semantic framing that the world's languages exhibit: verb-framed languages and satellite-framed languages. Verb-framed languages, also referred to as $V$-languages, include those that default to encoding path onto the main verb. Languages that have this frame include Romance varieties, Japanese, and Semitic. In verb-framed languages, other semantic properties,

\footnotetext{
* We are grateful to many people who contributed to this work, including members of the Child Language Lab and the Linguistics Research Group at William \& Mary for input on earlier versions of this work. Authors: Rebecca Smyder \& Kaitlyn Harrigan (kharrigan@wm.edu), William \& Mary.
} 
such as manner, are encoded on surrounding satellites such as prepositional or adverbial phrases (Cappelle 2012, Pedersen 2019, Schröder 2016, Talmy 2003). For example, French is among these languages (1).

(1) French (Cappelle 2012:5)

un OVNI passa à grande vitesse.

a UFO pass-PAST at great speed

'a UFO passed at great speed.'

In French, the path schema of the sentence 'pass' is encoded in the main verb, while the manner 'speed' is encoded onto a prepositional satellite (Cappelle 2012). Satellite-framed languages, or $S$-languages, show the opposite pattern. In these frames, path is encoded onto non-verbal satellites in the sentence, while manner may be encoded onto the main verb. Chinese (2) and English (3) are examples of languages that have a satellite-framed structure, along with some IndoEuropean languages (Schröder 2016, Shi \& Wu 2014, Slobin 2004, Talmy 2003).

(2) Chinese (Shi \& Wu 2014:1240)

tā zǒu chū le guānhăilóu.

3SG walk exit PFV sea-viewing tower

'He walked out of the sea-viewing tower.'

(3) She is running out of the house.

As with any grammatical structure, whether a language is verb-framed or satellite-framed is subject to change over time as the language evolves. Chinese evolved over time from a verb-framed language to a satellite-framed language. Like English, Modern Chinese encodes path onto nonverb satellites (Hohenstein et al. 2006, Shi \& Wu 2014).

Typological literature maintains the consensus that when a motion event is expressed in a language, directional features are considered the "core" lexical element (Talmy 2003; Johnson 1987). At minimum, motion events require two elements: path, which indicates trajectory, and ground, which indicates a point of orientation for the figure (Brown \& Gullberg 2010, Nakazawa 2007, Talmy 1991).

(4) His sister [figure] entered $_{[\text {path }]}$ the room $_{\text {[ground] }}$.

Manner, however, is considered optional in motion events. Manner can be added as a predicative satellite (5). Alternatively, it can be expressed in the main verb, while path is maintained in a predicative satellite (6).

(5) His sister ${ }_{[\text {figure] }}$ entered $_{[\text {path }]}$ the room $_{\text {[ground] }}$ hopping $_{[\text {manner } \text {. }}$.

(6) His sister ${ }_{[\text {figure }]}$ hopped $_{\left[\text {manner }_{1}\right.}$ into $_{[\text {path }}$ the room $_{\text {[ground] }}$.

The preferred structure of any given language is predicted by its typological categorization as a verb-frame or a satellite-frame language. Since path schema are considered the core of the sentence event, typologists observe that manner verbs show a great deal of diversity and nuance in satellite-frame languages (Cifuentes- Férez 2008, Slobin 2004). Manner verbs occur in one of two levels of lexical specificity: basic and non-basic. Basic verbs include those that express the most general sense of the action (e.g. walk, run, jump), whereas non-basic verbs are the variations of a basic verb (e.g. dash, jog, sprint are all second level verbs under run). Verb-frame languages tend to have a less diverse inventory of second-level manner verbs (Slobin 2004). Cross-linguistically, path verbs show little variation in the number of unique paths expressed by 
the language's verbs, which may be due to the finite number of possible paths in which a figure can move. For example, Spanish and English share 13 path types, including 'away from,' 'up/onto,' and 'to/towards;' however, Spanish tends to show more lexical variation within the inventory of these types than English (Cifuentes-Férez 2008, Selimis \& Katis 2010). Corpus studies have estimated English to contain about 20-44 path verbs while Spanish has upwards of 63 (Cifuentes-Férez 2008, Talmy 2003).

\subsection{LANGUAGE-SPECIFIC SENSITIVITY TO VERB FRAMING. Experimental work indicates that} speakers are sensitive to the verb-framing typology of their languages. A range of studies with adults have shown that speakers encode motion events differently depending on whether their native language is a verb-frame or an satellite-frame language (Ferez 2007, Maguire et al. 2010). In a cross-linguistic production study, Slobin (2006) found that when presenting an image of an owl flying out of a tree, satellite-frame speakers were much more likely to map manner onto the main verb of the sentence and indicate path in a satellite, while verb-frame speakers mapped path onto the main verb and often only indicated manner in the utterance unless it was emphasized by the image. This is consistent with theoretical work emphasizing the necessity of path over manner (Slobin 2006).

Other studies have utilized image description tasks studies to allow speakers an open-ended opportunity to encode a motion event with a path or manner verb. Naigles and Terrazas (1998) conducted a study with native monolingual English and Spanish speakers to observe the potential effects of verb type bias. Participants watched a series of motion events, each of which involving both a distinct manner and path (e.g. a woman skipping and moving toward a tree). The verb was given a novel name (e.g. Look! She's kradding!). The participants were then shown two test videos, one that demonstrated the correct path and one that demonstrated the correct manner, and instructed to indicate which of the two represented the sample video. English speakers were significantly more likely to choose the manner response than the path, while Spanish speakers were equally likely to select the manner or the path response. Studies like these clearly demonstrate that typology can lead to a verb type bias in event encoding.

1.3. ACQUISITION OF MOTION VERBS. Learning verb meanings poses a particularly complex set of challenges to the child - verbs involve multiple participants, and require sensitivity not just to a category of object but to recognizing which of infinite components in a scene are relevant to the verb's meaning. This difficulty is reflected in the acquisition trajectory - although infants are tracking movement and events from infancy (Baillargeon 1987, Bertenthal et al. 2013, Bower et al. 1971, Pulverman 2005), they do not begin to map these events to verbs until much later (Behrend 1990, Hirsh-Pasek \& Golinkoff 2010). This happens much later than they are mapping nouns to objects (Cartmill et al. 2014, Gleitman et al. 2005, Holowka et al. 2002). This noun advantage has been well documented in the language acquisition literature.

Prior studies have specifically investigated children's sensitivity to manners and paths of movement and their ability to map those concepts to verbs. Pulverman et al. (2008) demonstrated that children even as young as 9 months were able to detect changes in manner and path. They conducted a visual fixation paradigm task where the child was presented with scenes that changed in manner, path, both, or neither. Both English-exposed and Spanish-exposed infants showed this same sensitivity. Language studies conducted with older children indicate that children begin to show language-specific bias for this typology between 3 and 7 years of age, and that before this point they show a path-bias - defaulting to encoding the path of motion over manner regardless of their language's typology (Allen et al. 2007, Skordos \& Papafragou 2014). 
Studies also indicate that perceptual sensitivity to aspects of motion may be separate from the process of linguistic encoding. In a study investigating English and Greek adult and 5-yearolds' interpretation of motion events, researchers found a disconnect between speakers' categorization preferences depending on whether the task involved verb mapping. Greek, like Spanish, is a verb-frame language. Speakers of both English and Greek preferred to categorize by the path of motion when the task did not require mapping to a verb, but were more likely to categorize based on their language typology in a linguistic task. These results suggest that bias toward manner interpretations is learned and language-specific (Papafragou \& Selimis 2009). Research with children suggests that the cognitive underpinnings for sensitivity to path and manner are in place early, and even prioritize encoding path of motion. As children advanced in their language development, they begin to refine their encoding of motion events to be more closely in line with their language's typology.

\subsection{THE CURRENT STUDY. The main goal of this study is to investigate children's sensitivity to} the bias from their own language typology in mapping novel verbs. Children will see a series of familiarization videos, in which an agent performs an intransitive motion event. The familiarization videos on each trial will be matched on either path or manner, therefore creating unambiguous evidence (at least for the relevance of path v. manner) for the novel verb's meaning. This will allow us to compare accuracy of mapping manner and path verbs in Englishlearning children, who begin with the universal path-bias, but at some point begin to default to encoding manner.

An additional factor was introduced in order to better contextualize children's "preferences" for encoding motion type as the relevant aspect of an event. We counterbalance motion type with an environmental factor-either the agent or the location served as a "distractor" from the motion type. This ensured that children's accuracy in mapping motion was not simply an artifact of surface-level similarity across familiarization and test. We hypothesize, however, that the two levels of the environmental factor will not be treated equally by the child. The agent of an event is unlikely to be relevant to a verb's meaning, but the location of an event is a potentially relevant component. Some verbs, like swim, hike or fly require certain types of locations in order to be performed. We therefore additionally hypothesize that children will be less accurate, i.e. more likely to be distracted by the environment in the location trials compared to the person trials.

2. Experiment. The current study investigates English-learning children's sensitivity to path and manner properties in verb learning when presented with a set of events that unambiguously portrays either a consistent manner or path of motion, and compared sensitivity to these properties to two different distractor properties: the identify of the agent and the location of the events.

2.1. SuBJECTS. Participants were 20 monolingual English-learning preschool and elementary children aged 4;0-7;10 (mean $=5.02)$ recruited from the Williamsburg, VA area, and tested either at their local preschools or in the Child Language Lab at William \& Mary. Participants were only run if they gave verbal assent and the researchers had received a completed consent form from the parent or legal guardian.

2.2. PRocedure. Each of the participants was shown the same series of short videos, consisting of 8 trials. Two pseudo-randomized orders of trials were randomly assigned to participants. The videos were played on a laptop placed directly in front of the child so that they could point to indicate their answers on the screen. All participants were given the option to stop the activity at any time. All participants were run either in a quiet testing room in the William \& Mary Child Language Lab or in a relatively quiet room in their school. 
2.3. Design AND MATERIALS. The current study features a $2 \times 2$ design. We manipulate within subjects MOTION TYPE (PATH V MANNER) and the "distractor" variable of ENVIRONMENT (LOCATION V PERSON). In a forced-choice task, each of the 8 trials consists of three video clips depicting intransitive events named by a novel verb.

(7) Look she's rizzing! She's rizzing again. She's rizzing here too.

The three events always match on VERB TYPE and on ENVIRONMENT. During the test phase, the child sees two simultaneous videos on the screen, and must choose which one is the best example of the new verb depicted in the familiarization trials. One of the videos matches the familiarization trials in VERB TYPE, and the other matches in ENVIRONMENT.

Which one is rizzing? Can you find rizzing?

The design is completely counterbalanced: participants saw two trials for each of the four combinations (Table 1).

\begin{tabular}{ccc}
\hline MOTION TYPE & ENVIRONMENT & number of trials \\
\hline \multirow{2}{*}{ path } & person & 2 \\
\cline { 2 - 3 } & location & 2 \\
\hline \multirow{2}{*}{ manner } & person & 2 \\
\cline { 2 - 3 } & location & 2 \\
\hline
\end{tabular}

Table 1. Number of trials by condition.

Sample events for two of the combinations are shown in Figure 1: path/person and manner/location. In each case, on the test trial, one video is consistent with the MOTION TYPE from test, and the other video is consistent with the ENVIRONMENT. This allows us to test both accuracy of mapping MOTION TYPE, as well as the strength of each of the ENVIRONMENT factors as a potential distractor to mapping the motion type. 


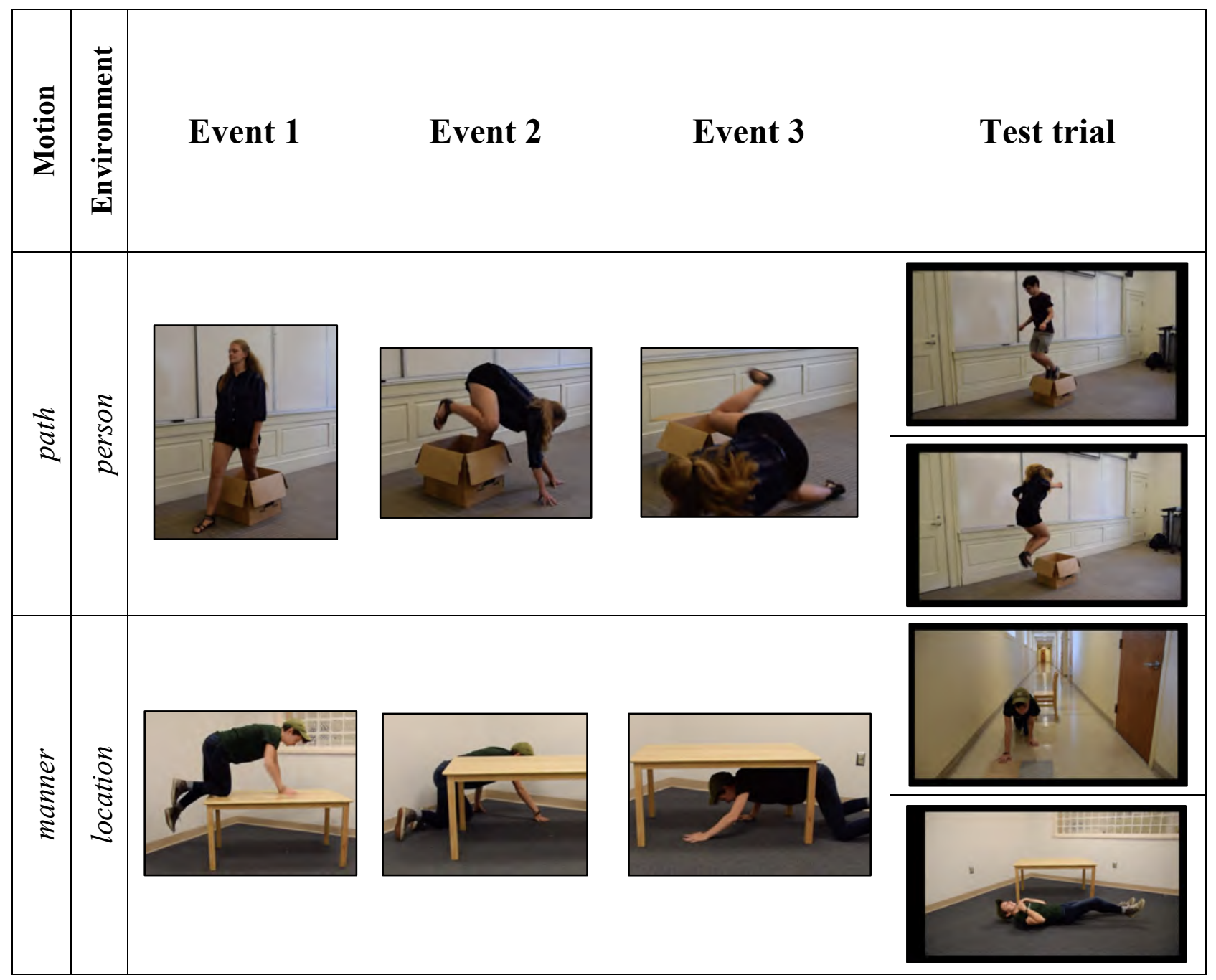

Figure 1. Sample events from path/person and manner/location conditions.

2.4. PREDICTIONS. The main hypothesis predicts a difference in performance based on MOTION TYPE (PATH V MANNER). English-learning children are exposed to more verbs denoting manner, and should therefore be more accurate in learning new manner verbs compared to path verbs. In the current study, they should be more likely to be lured away from mapping the MOTION TYPE in the PATH compared to the MANNER conditions. In addition, we predict one type of ENVIRONMENT distractor to be more distracting than the other: some verbs may require information about the location, but verbs are unlikely to require specific agents. Therefore, we predict that children may be more likely to be lured by the distractor in the LOCATION trials than the PERSON trials. This might manifest as main effect: LOCATION trials may be overall more difficult than PERSON trials. We might also see this manifest as an interaction: the combination of PATH/LOCATION may be particularly challenging for English-learning children given the combination of their language-specific manner-bias as well as the more universal bias of location as a potentially relevant factor in verb-meaning.

2.5. RESULTS. Children's responses were coded as the child delivered the response by the experimenter. We find, as predicted, that English-learning children are more accurate at mapping manner compared to path events (Table 2, Figure 2). 


\begin{tabular}{cc}
\hline MOTION TYPE & accuracy \\
\hline path & 0.65 \\
\hline manner & 0.82 \\
\hline
\end{tabular}

Table 2. Proportion accurate responses for MOTION TYPE conditions.

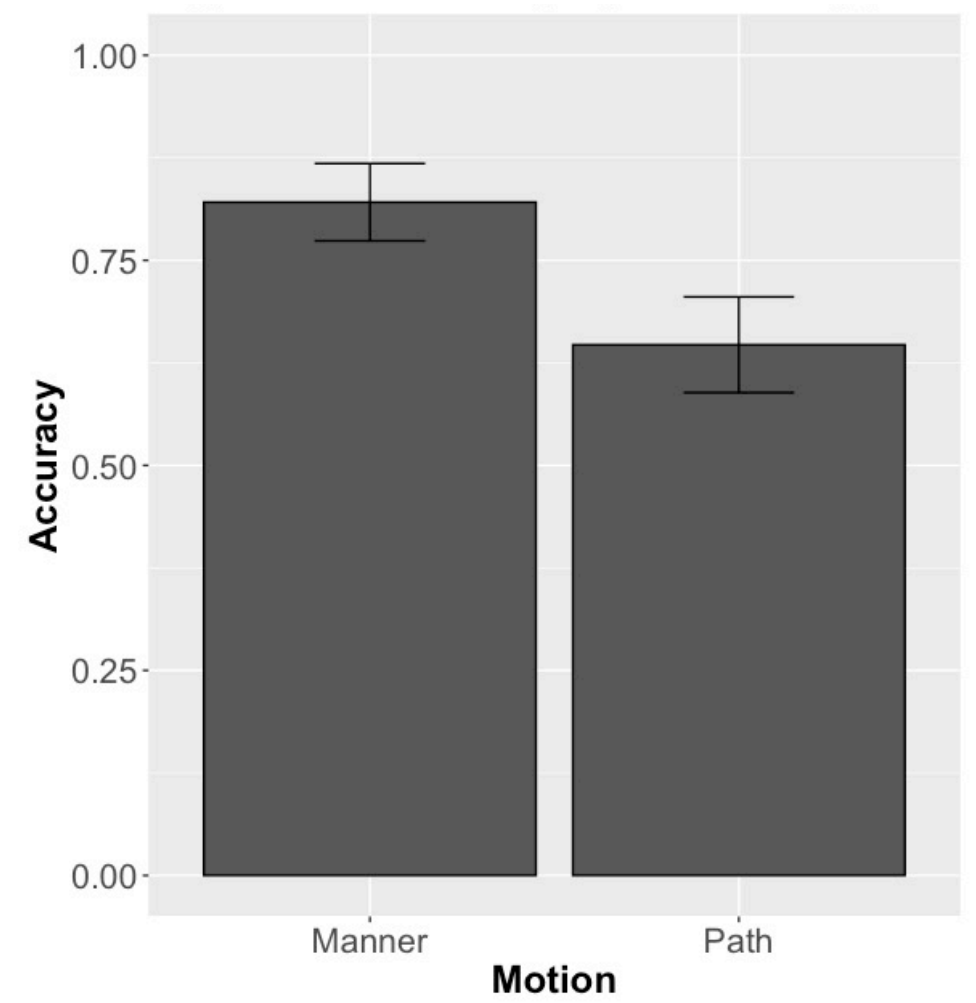

Figure 2. Proportion accurate responses for MOTION TYPE conditions.

We also find that children are more likely to be lured by the ENVIRONMENT factor in the LOCATION compared to the PERSON trials (Table 3, Figure 3). In other words, it is easiest to override the ENVIRONMENT distractor when English-learning children are learning a manner verb, and when the location is consistent.

\begin{tabular}{ccc}
\hline MOTION TYPE & ENVIRONMENT & $\begin{array}{c}\text { accuracy } \\
(\% \text { motion responses })\end{array}$ \\
\hline \multirow{2}{*}{ path } & person & 0.68 \\
\cline { 2 - 3 } & location & 0.62 \\
\hline \multirow{2}{*}{ manner } & person & 0.91 \\
\cline { 2 - 3 } & location & 0.73 \\
\hline
\end{tabular}

Table 3. Results of MOTION TYPE and ENVIRONMENT conditions. 


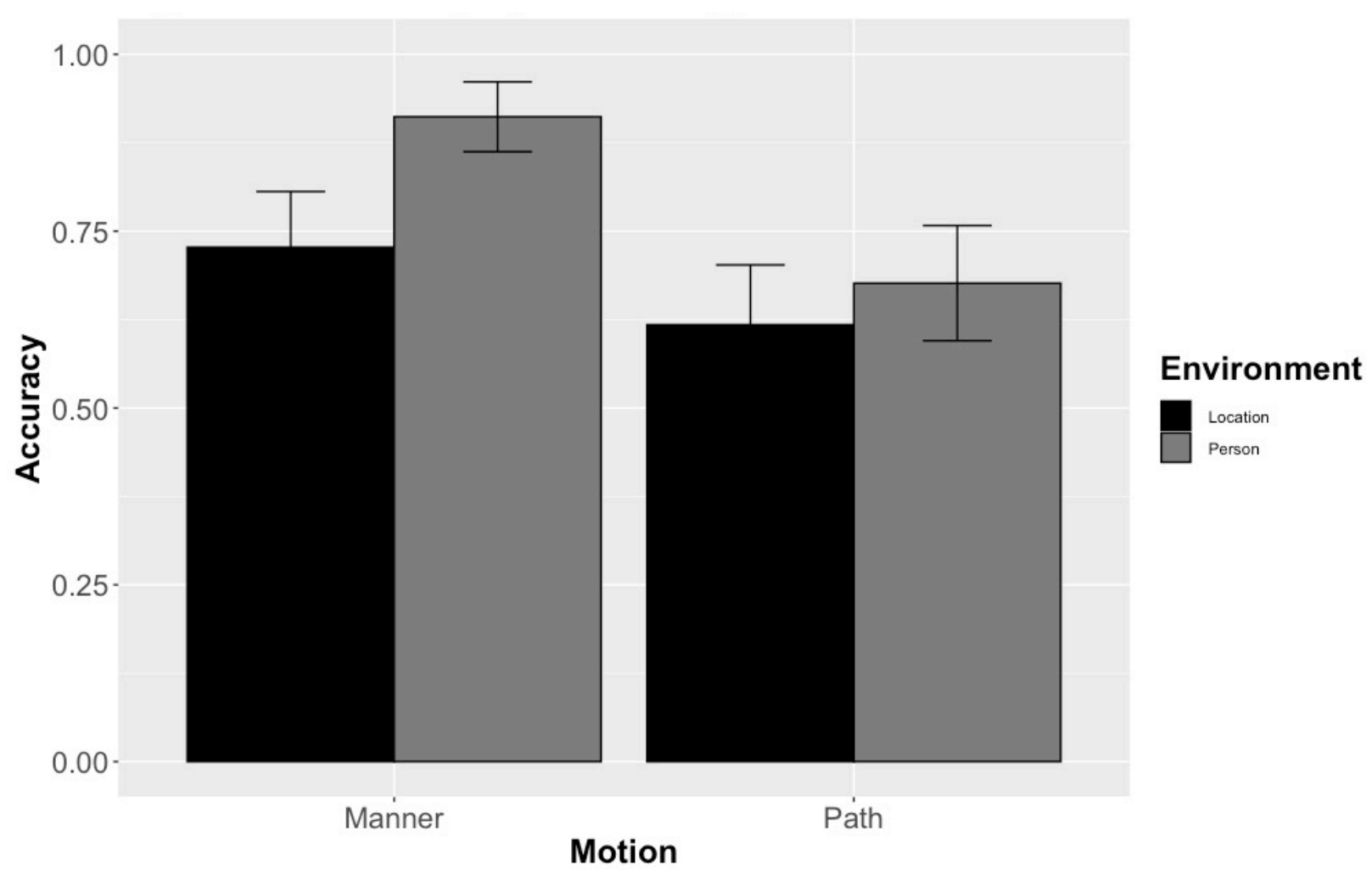

Figure 3. Results of MOTION TYPE and ENVIRONMENT conditions.

2.6. Statistical Analysis. Statistical analyses also support the above findings. The results were analyzed using a generalized linear mixed effects model, which is a model appropriate for analyzing categorical data (Baayen, 2007; Jaeger, 2008). The reported models have random intercepts. These models predict the probability of a specific response (a correct answer) across different conditions (see Agresti, 2002; Jaeger, 2008). We ran a mixed-effect logit model with correct response as the dependent measure, with MOTION TYPE and ENVIRONMENT as fixed effects, and SUBJECT as a random effect. We find a main effect of MOTION TYPE

$\left[\mathrm{X}^{2}{ }_{(1)}=5.23, p=0.022\right]$, indicating that participants are significantly more likely to accurately map the motion over the environment in the manner compared to the path condition. We also find a marginal main effect of ENVIRONMENT $\left[\mathrm{X}_{(1)}^{2}=3.65, p=0.056\right]$, indicating that participants are marginally more likely to be lured by location than person. We find no interaction between MOTION TYPE and ENVIRONMENT, indicating that there is no significant difference in likelihood of responses based on the combination of motion and environment $\left[\mathrm{X}_{(1)}^{2}=1.58, p=0.209\right]$.

The statistical models confirm the main hypothesis of this work: children who are exposed to a manner-biased language like English are better at mapping manner events to verbs than they are at mapping path events. We also see some preliminary findings suggesting that the different environmental factors are used differentially by the learner - the agent performing the action is much less likely to be relevant to the verb meaning than the location of the event. This is captured by the difference in accuracy across the PERSON and LOCATION trials.

2.7. SuMmARY. In a forced-choice task pitting motion types against environmental factors, we find that English-learning children are significantly more accurate at mapping the manner of an event to a novel verb than the path of an event. We also find some preliminary results suggesting 
that children are sensitive to environmental factors in mapping verbs: they are more likely to be lured by the location of an event than they are by the identity of the agent performing the action.

3. Discussion. The findings of the current study are consistent with other reports of children's language-specific motion verb biases. During late preschool or early elementary school years, children's mapping of motion events to verbs becomes attuned to the typological preference of their language. Although all children start with a bias toward encoding paths over manner (and, this biases persists in non-linguistic tasks), English-leaning children and English-speaking adults show preference for mapping manners over paths in ambiguous contexts. The findings of this study extend on these earlier findings by showing that English-learning children's bias toward manners goes beyond a preference, and manifests in differences in accuracy in mapping manners v. paths in unambiguous contexts. This finding satisfies the main prediction of our study.

We also found that children are differentially sensitive to aspects of the event extra to the motion type. In particular, we find that while they are extremely robust in ignoring a change in the identity of the agent, they are more likely to be "lured" by the event taking place in a new location. We hypothesize that this is based on the likely universal possibility of verbs requiring specific locations in order to be executed, as compared to the very unlikely case of verbs requiring a specific agent.

3.1. REMAINING QUESTIONS. The current study sought to explore English-learning children's sensitivity to manner and path in mapping novel verbs, but also introduced the language universal environmental factors of location and agent identity. We find, as predicted, that they are better at rejecting a change of agent as a relevant component to verb meaning than they are at rejecting location. This suggests that, at least under some circumstances, children are sensitive to the location of an event during the mapping of that event to a novel verb. Current ongoing work on our lab aims to expand on these findings in children and in adults. For adults, we are investigating how the environment of various motion events affects their mappings to verbs. For example, is a "swimming" motion still rated as swimming if it takes place in the air? On the ground? What about walking? Or flying? This work will help us better understand the role of location in the semantic representation in adults, which will in turn guide future studies investigating mapping in children.

4. Conclusion. The current study compared English-speaking children's mapping of novel motion verbs to either path or manner events. We find that children are sensitive to the languagespecific manner bias in English — showing higher accuracy for mapping manner verbs than path verbs. We also find that children are sensitive to environmental factors in mapping these novel motion events. They are more likely to be lured or distracted by a location change than a change in the identity of an agent. The comparison of these factors indicates both language-specific as well as universal cues as constraints on mapping verb meanings.

\section{References}

Agresti, Alan. 2002. Categorical data analysis. 2nd Edn. New York, NY: Wiley.

Allen, Shanley, Asli Özyürek, Sotaro Kita, Amanda Brown, Reyhan Furman, Tomoko Ishizuka \& Mihoko Fujii. 2007. Language-specific and universal influences in children's syntactic packaging of manner and path: A comparison of English, Japanese, and Turkish. Cognition 102(1). 16-48. https://doi.org/10.1016/j.cognition.2005.12.006.

Baayen, R. Harald. 2007. Analyzing linguistic data: A practical introduction to statistics. Cambridge: Cambridge University Press. 
Baillargeon, René. 1987. Object permanence in 31/2- and 41/2-month-old infants. Developmental Psychology 23(5). 655-664. https://doi.org/10.1037/0012-1649.23.5.655.

Behrend, Douglas, A. 1990. The development of verb concepts: Children's use of verbs to label familiar and novel events. Child Development 61(3). 681-69. https://doi.org/10.2307/1130953.

Bertenthal, Bennett, Gustaf Gredebäck \& Ty W Boyer. 2013. Differential contributions of development and learning to infants' knowledge of object continuity and discontinuity. Child Development 84(2). 413-421. https://doi.org/10.1111/cdev.12005.

Bower, T. G., J. Broughton \& M. K. Moore. 1971. Development of the object concept as manifested in changes in the tracking behavior of infants between 7 and 20 weeks of age. Journal of Experimental Child Psychology 11(2). 182-193.

Brown, Amanda \& Marianne Gullberg. 2010. Changes in encoding of path of motion after acquisition of a second language. Cognitive Linguistics 21(2). 263-286. https://doi.org/10.1515/COGL.2010.010.

Cappelle, Bert. 2012. English is less rich in manner-of-motion verbs when translated from French. Across Languages and Cultures 13(2). 173-195.

Cartmill, Erica, Dea Hunsicker \& Susan Goldin-Meadow. 2014. Pointing and naming are not redundant: Children use gesture to modify nouns before they modify nouns in speech. Developmental Psychology 50(6). 1660-1666. https://doi.org/10.1037/a0036003.

Cifuentes-Férez, Paula. 2007. Human locomotion verbs in English and Spanish. International Journal of English Studies 7(1). 117+. https://revistas.um.es/ijes/article/view/48931.

Cifuentes-Férez, Paula. 2008. Motion in English and Spanish: A perspective from cognitive linguistics, typology and psycholinguistics. Murcia, ES: Universidad de Murcia dissertation.

Gleitman, Lila R., Kimberly Cassidy, Rebecca Nappa, Anna Papafragou \& John C. Trueswell. 2005. Hard words. Language Learning and Development 1(1). 23-64. https://doi.org/10.1207/s154733411ld0101 4.

Hirsh-Pasek, Kathryn \& Roberta M. Golinkoff. 2010. Action meets word: How children learn verbs. Oxford: Oxford University Press. https://doi.org/10.1093/acprof:oso/9780195170009.001.0001.

Hohenstein, Jill, Ann Eisenberg \& Letitia R. Naigles. Is he floating across or crossing afloat? Cross-influence of L1 and L2 in Spanish-English bilingual adults. Bilingualism: Language and Cognition 9(3). 249-261. https://doi.org/10.1017/S1366728906002616.

Holowka, Siobhan, Françoise Brosseau-Lapré \& Laura Ann Petitto. 2002. Semantic and conceptual knowledge underlying bilingual babies' first signs and words. Language Learning 52(2). 205-262. https://doi.org/10.1111/0023-8333.00184.

Jaeger, T. Florian. 2008. Categorical data analysis: Away from ANOVAs (transformation or not) and towards Logit Mixed Models. Journal of Memory and Language 59. 434-446. https://doi.org/10.1016/j.jml.2007.11.007.

Johnson, Mark. 1987. The body in the mind: The bodily basis of meaning, imagination and reasoning. Chicago: University of Chicago Press.

Maguire, Mandy J., Kathryn Hirsh-Pasek, Roberta M. Golinkoff, Mutsumi Imai, Etsuko Haryu, Sandra Vanegas, Hiroyuki Okada, Rachel Pulverman \& Brenda Sanchez-Davis. 2010. A developmental shift from similar to language-specific strategies in verb acquisition: A comparison of English, Spanish, and Japanese. Cognition 114(3). 299-319. https://doi.org/10.1016/j.cognition.2009.10.002. 
Naigles, Letitia R. \& Paula Terrazas. 1998. Motion-verb generalizations in English and Spanish: Influences of language and syntax. Psychological Science 9(5). 363-369. https://doi.org/10.1111/1467-9280.00069.

Nakazawa, Tsuneko. 2007. A typology of the ground of deictic motion verbs as path-conflating verbs: The speaker, the addressee, and beyond. Poznan Studies in Contemporary Linguistics 43(2). 59-82. https://doi.org/10.2478/v10010-007-0014-3.

Papafragou, Anna \& Stathis Selimis. 2009. On the acquisition of motion verbs cross-linguistically. Proceedings of the 8th International Conference on Greek Linguistics. 351-365.

Pedersen, Johan. 2019. Verb-based vs. schema-based constructions and their variability: On the Spanish transitive directed-motion construction in a contrastive perspective. Linguistics 57(3). 473-530. https://doi.org/10.1515/ling-2019-0007.

Pulverman, Rachel. 2005. The relationship between language development and event processing: Lexical acquisition and attention to manner and path. Newark, DE: University of Delaware dissertation.

Pulverman, Rachel, Roberta M. Golinkoff, Kathryn Hirsh-Pasek \& Jennifer Sootsman Buresh. 2008. Infants discriminate manners and paths in non-linguistic dynamic events. Cognition 108(3). 825-830. https://doi.org/10.1016/j.cognition.2008.04.009.

Schröder, Helga. 2016. Motion in Toposa: Is Toposa a verb frame or satellite frame language? Lodz Papers in Pragmatics 12(2). 153-175. https://doi.org/10.1515/lpp-2016-0010

Selimis, Stathis \& Demetra Katis. 2010. Motion descriptions in English and Greek: A cross-Typological developmental study of conversations and narratives. Linguistik Online 42(2). 53-72. https://doi.org/10.13092/lo.42.421.

Shi, Wenlei \& Yicheng Wu. 2014. Which way to move: The evolution of motion expressions in Chinese. Linguistics 52(5). 1237-292. https://doi.org/10.1515/ling-2014-0024.

Skordos, Dimitrios \& Anna Papafragou. 2014. Lexical, syntactic, and semantic-geometric factors in the acquisition of motion predicates. Developmental Psychology 50(7). 1985-1998. https://doi.org/10.1037/a0036970.

Slobin, Dan Isaac. 2004. How people move. In Carol Lynn Moder \& Aida Martinovic-Zic (eds.), Discourse across languages and cultures, 195-210. Amsterdam: John Benjamins. https://doi.org/10.1075/slcs.68.11slo.

Slobin, Dan Isaac. 2006. What makes manner of motion salient: Explorations in linguistic typology, discourse, and cognition. In Maya Hickmann \& Stéphane Robert (eds.), Space in languages: Linguistic systems and cognitive categories, 59-81. Amsterdam: John Benjamins.

Talmy, Leonard. 1991. Path to realization: A typology of event conflation. Berkeley Linguistics Society (BLS) 17. 480-519. https://doi.org/10.3765/bls.v17i0.1620.

Talmy, Leonard. 2003. Toward a cognitive semantics: Typology and process in concept structuring. (Vol. 2). Cambridge, MA: MIT Press. 